\title{
Validation of Petroleum Hydrocarbons Determination in Wastewaters By FT-IR Spectroscopy
}

\author{
Claudiu TĂNĂSELIA*, Erika LEVEI, Marin ȘENILĂ, Oana CADAR \\ INCDO INOE 2000, Research Institute for Analytical Instrumentation, ICIA, Donath 67, Cluj-Napoca, \\ Romania \\ *Corresponding author: claudiu.tanaselia@icia.ro
}

Bulletin USAMV series Agriculture 72(2)/2015

Print ISSN 1843-5246; Electronic ISSN 1843-5386

DOI 10.15835/buasvmcn-agr: 10431

\begin{abstract}
Water contamination with petroleum hydrocarbons is one of the most challenging environmental problems, as crude oil continues to be the main source of energy and petrochemicals. This study presents the validation and the estimation of the measurement uncertainty for the determination of petroleum hydrocarbons in water samples by Fourier Transform Infrared Spectrometry (FT-IR). Method for petroleum hydrocarbons determination from water consist in the acidification of the sample $(\mathrm{pH}<5)$, extraction of 1 liter of water sample with $50 \mathrm{ml}$ of carbon tetrachloride, removal of polar substances by Florisil column filtration and measurement of the IR absorption within the 3150-2750 $\mathrm{cm}^{-1}$ range. The measurements were carried out using a Perkin Elmer Spectrum BX II FTIR spectrometer. For the method validation detection limit and quantification limit, working range, trueness and precision were studied. The measurement uncertainty was evaluated based on the bottom-up approach. The detection limit was calculated to be $0.1 \mathrm{mg} / \mathrm{l}$ and the quantification limit $0.3 \mathrm{mg} / \mathrm{l}$. Working range was set between 0.3 and $10 \mathrm{mg} / \mathrm{l}$ and samples with higher concentrations can be determined after appropriate dilution to fit within these limits. Relative standard deviation for repeatability was $6.4 \%$ for the $0.3-4 \mathrm{mg} / \mathrm{l}$ range and $6.0 \%$ for $4-10$ $\mathrm{mg} / \mathrm{l}$ range. The expanded uncertainty of this method is $13.5 \%$ for $\mathrm{LQ}-4 \mathrm{mg} / \mathrm{l}$ range and $12.5 \%$ for $4-10 \mathrm{mg} / \mathrm{L} \mathrm{range}$ (at $95 \%$ confidence level, $\mathrm{k}=2$ ).
\end{abstract}

Keywords: FT-IR spectroscopy, Method validation, Petroleum hydrocarbons, Water samples.

\section{INTRODUCTION}

Petroleum hydrocarbons is a term that covers a broad family of chemicals, from compounds of biogenic origin to mineral hydrocarbon constituents (Farmaki et al., 2007). These substances may enter the environment by leakage, spilling, improper storage or any other accident and pose a real danger for the ecosystem.

The major oil spill incidents include the one in Gulf of Mexico and the oil pipeline explosion in Dalian City, Liaoning Province, China (Tang et al., 2012).

Petroleum hydrocarbons effects on living organisms varies from destruction of algae and plankton, changes in feeding and reproduction of water life (plant, insect, and fish) (API, 2001, Clinton et al., 2009), to direct effects on human health, as fatigue, headache, nausea, drowsiness, and affect central nervous system, immune system, liver, spleen, kidneys and lungs (ATSDR, 2009).

Thus, a fast and relatively cheap method for petroleum hydrocarbon determination in wastewaters is a very useful tool for analytical laboratories dealing with this pollutant agent and FT-IR technique provide such an analysis method.

\section{MATERIALS AND METHODS}

Petroleum hydrocarbons determination from water is accomplished by extraction of 1 liter of water sample with $50 \mathrm{ml}$ of carbon tetrachloride under continuous shaking, for 30 minutes. The sample must have $\mathrm{pH}$ value lower than 5 (obtainable using hydrochloric acid). The polar substances are removed by using Florisil column 
filtration after the extraction and water excess is removed by using anhydrous sodium sulphate. The IR absorption spectrum is measured, within the $3150-2750 \mathrm{~cm}^{-1}$ range, using a quartz cell of 1 $\mathrm{cm}$ length and a Perkin Elmer Spectrum BX II FTIR spectrometer (). All reagents were purchased from Merck and were of p.a quality.

\section{RESULTS AND DISCUSSION}

For determination of detection and quantification limits, 10 independent blank solutions have been spiked with $0.05 \mathrm{mg} / \mathrm{l}$ TPH (1/1 diesel oil/ lubricating oil mixture (BAMK010e, Federal Institute for Materials Research and Testing, Germany) and their absorbance recorded. Detection limit $(0.1 \mathrm{mg} / \mathrm{l})$ was calculated using the three standard deviation criteria (3s) and further on, quantification limit $(0.3 \mathrm{mg} / \mathrm{l})$ was determined by the nine standard deviation criteria (9s). The obtained value for quantification limit was confirmed by preparing 10 solutions with a TPH concentration of $0.3 \mathrm{mg} / \mathrm{l}$ and the obtained relative standard deviation was below $5 \%$, while the recovery were within 80 $120 \%$ of the theoretical value, thus validating the value for the quantification limit.

Working range was set between $0.3-10$ $\mathrm{mg} / \mathrm{l}$, which can be further extended using sample dilution. For linearity domain verification, a number of 5 solutions were prepared, with concentration of $0.01,0.02,0.05,0.1$ and $0.2 \mathrm{mg} /$ $\mathrm{ml}$, using a mix of Diesel and mineral oil (1:1), BAMK010e certified reference material. The squared ratio of standard deviation between the highest and the lowest point on the calibration curve was determined to be below 5 , which proves that the domain was correctly chosen and its linearity is ensured.

Repeatability was verified by using aliquot samples for two levels of concentration within the work domain and the relative standard deviation was below $10 \%$ for both cases. Further on, intermediary repeatability was verified, by measuring a stable, certified sample over a period of 10 days. The NG 11 filter (polystyrene traceable reference material Perkin Elmer PE08280) was chosen for this task and the relative standard deviation found 10 days was $0.072 \%$.

Reproducibility was checked by participating in Proficiency Test Scheme (Aquacheck, LGC Promochem, UK). The Z-score value is within -1 and +1 interval, which indicates a good agreement with indicative values.

A number of two samples were spiked with $2.3 \mathrm{mg} / \mathrm{l}$ and $6.4 \mathrm{mg} / \mathrm{l}$ petroleum products, in order to determine the recovery. The results for the recovery value were $82 \%$, respectively $83 \%$.

Tab. 1. Measurements of 10 independent samples for detection limit and quantification limit determination, in both $\mathrm{mg} / \mathrm{ml}$ (as determined by reading the sample directly) and $\mathrm{mg} / \mathrm{l}$ (the final result, after considering the volume of the sample and flasks)

\begin{tabular}{|c|c|c|}
\hline & Result (mg/ml) & Results (mg/l) \\
\hline 1 & 0.0015 & 0.075 \\
\hline 2 & 0.0016 & 0.080 \\
\hline 3 & 0.0015 & 0.075 \\
\hline 4 & 0.0010 & 0.050 \\
\hline 5 & 0.0025 & 0.125 \\
\hline 6 & 0.0008 & 0.040 \\
\hline 7 & 0.0006 & 0.030 \\
\hline 8 & 0.0008 & 0.040 \\
\hline 9 & 0.0016 & 0.080 \\
\hline 10 & 0.0023 & 0.115 \\
\hline $\mathbf{s}$ & 0.00064 & 0.032 \\
\hline LD (3s) & 0.002 & 0.1 \\
\hline LQ (9s) & 0.006 & 0.3 \\
\hline
\end{tabular}




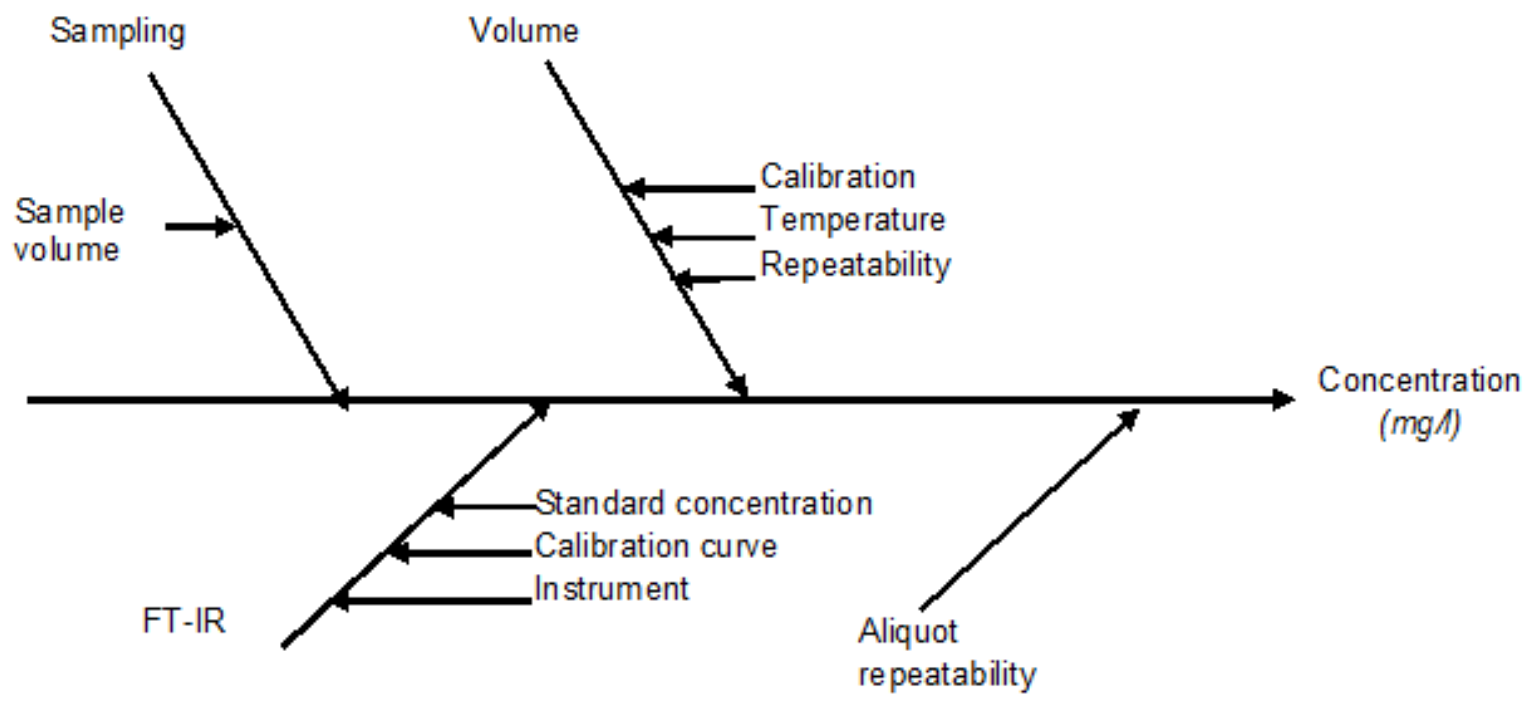

Fig. 1. Cause and effects diagram of uncertainties

The uncertainty budget comprised of various sources: purity of reference material, weighting uncertainty, volume of liquid use in standard preparation, sample volume, FT-IR instrument uncertainty, calibration curve uncertainty and aliquot sample repeatability (visually described in Fig. 1).

All these were taken into account and calculation was made according to Eurachem guide (Ellison et al., 2012). Extended uncertainty for of petroleum hydrocarbons determination in wastewaters using the described method was found to be $0.702 \mathrm{mg} / \mathrm{l}$ which translates to a $12.5 \%$ relative extended uncertainty.

\section{CONCLUSION}

The detection limit for the determination of petroleum hydrocarbons in soil was found to be $0.1 \mathrm{mg} / \mathrm{l}$ and the quantification limit 0.3 $\mathrm{mg} / \mathrm{L}$. The working domain was found to be linear between 0.3 and $10 \mathrm{mg} / \mathrm{l}$, but solutions with higher concentrations can be analyzed after dilution. Recovery (\%) of petroleum hydrocarbons in water samples calculated in spiked wastewater was $82 \pm 10 \%$. Relative standard deviation for repeatability was $6.4 \%$ for the $0.3-4 \mathrm{mg} / \mathrm{l}$ range and $6.0 \%$ for $4-10 \mathrm{mg} / \mathrm{l}$ range. Reproducibility was determined by measuring a certified filter supplied by vendor and the relative standard deviation obtained was 0.07 . Z-score for interlaboratories studies was -0.59 . The expanded uncertainty of this method is $13.5 \%$ for $0.3-4 \mathrm{mg} / \mathrm{l}$ range and $12.5 \%$ for $4-10 \mathrm{mg} / \mathrm{l}$ range (at $95 \%$ confidence level, $\mathrm{k}=2$ ).

The FT-IR method for the determination of petroleum hydrocarbons in water samples was validated. The method's figures of merit were studied, the main uncertainty components were identified and the measurement uncertainty budget was estimated. The FT-IR method allows the accurate determination of petroleum products from water samples.

Acknowledgments. This work was supported by Romanian financing authority CNCS -UEFISCDI, Partnership program, project BIORESOL

\section{REFERENCES}

1. Farmaki E, Kaloudis $\mathrm{T}$, Dimitrou $\mathrm{K}$, Thanasoulias $\mathrm{N}$, Kousouris L, Tzoumerkas F (2007). Validation of a FTIR method for the determination of oils and grease in water using tetrachloroethylene as the extraction solvent. Desalin, 210:52-60

2. Tang SL, Zhang Y, Zhong S, Li AM (2012). A novel infrared spectrophotometric method for the rapid determination of petroleum hydrocarbons, and animal and vegetable oils in water, Chinese Chemical Letters, 23(1):109-112

3. Clinton HI, Ujagwung GU, Horsfall M (2009). Evaluation of total hydrocarbon levels in some aquatic media in an oil 
polluted mangrove wetland in the Niger Delta, Appl Ecol Environ Res, 7:111-120

4. Ellison SLR, Williams A (2012). Eurachem/CITAC guide: Quantifying Uncertainty in Analytical Measurement, Third edition, ISBN 978-0-948926-30-3.

5. ***, API (2001). Effects of oil and chemically dispersed oil in the environment, Health and Environmental Sciences
Department, Scientific and Environmental Associates, Inc., Cape Charles, Virginia, American Petroleum Institute.

6. ***, ATSDR (1999). Public Health Statement for Total Petroleum Hydrocarbons (TPH), U.S. Department of Health and Human Services, Public Health Service, Atlanta, Georgia, Agency for Toxic Substances and Disease Registry. 